\title{
(Lymph)angiogenic influences on hematopoietic cells in acute myeloid leukemia
}

\author{
Ji Yoon Lee and Hee-Je Kim
}

The purpose of this review is to provide an overview of the effect of (lymph)angiogenic cytokines on hematopoietic cells involved in acute myeloid leukemia ( $\mathrm{AML}$ ). Like angiogenesis, lymphangiogenesis occurs in pathophysiological conditions but not in healthy adults. AML is closely associated with the vasculature system, and the interplay between lymphangiogenic cytokines maintains leukemic blast survival in the bone marrow (BM). Once AML is induced, proangiogenic cytokines function as angiogenic or lymphangiogenic factors and affect hematopoietic cells, including BM-derived immune cells. Simultaneously, the representative cytokines, VEGFs and their receptors are expressed on AML blasts in vascular and osteoblast niches in both the BM and the peripheral circulation. After exposure to (lymph)angiogenic cytokines in leukemogenesis and infiltration, immune cell phenotypes and functions are affected. These dynamic behaviors in the BM reflect the clinical features of AML. In this review, we note the importance of lymphangiogenic factors and their receptors in hematopoietic cells in AML. Understanding the functional characterization of (lymph)angiogenic factors in the BM niche in AML will also be helpful in interrupting the engraftment of leukemic stem cells and for enhancing immune cell function by modulating the tumor microenvironment. Experimental \& Molecular Medicine (2014) 46, e122; doi:10.1038/emm.2014.72; published online 21 November 2014

\section{INTRODUCTION}

Acute myeloid leukemia (AML) is aggressively malignant and is closely associated with increased microvessel density in the bone marrow (BM). ${ }^{1-3}$ Most hematologic malignancies, including AML, are associated with angiogenesis in peripheral organs as well as the BM. The human body contains two major vasculatures: the blood vessels and the lymphatic vessels. In embryonic mouse development, blood vessels are formed by the differentiation of endothelial precursors, called angioblasts. This process, called vasculogenesis, is the formation of new blood vessels from stem/progenitor cells. Angiogenesis, the process of the formation of new blood vessels from preexisting blood vessels, commonly occurs postnatally in tumors and in inflammation. Folkman et al. ${ }^{4}$ first addressed the concept of angiogenesis, leading to many studies, from basic science to clinical applications, to treat both hematologic malignancies and solid tumors. Similarly, Sabin FR, who described the embryonic origin of lymphatic vessels in 1902, addressed the venous origin of lymphatic vasculature in mammals as well as blood vessel formation. ${ }^{5}$ Lymphatic vessel formation is also divided into two processes, called lymphangiogenesis and lymphvasculogenesis. ${ }^{6}$ Lymphangiogenesis in the embryo and in postnatal stages initiates from the cardinal vein and preexisting lymphatic vessels, respectively, in response to VEGF-C stimulation. ${ }^{7-9}$ The VEGF-C or D/VEGFR-3 axis is a dominant driver of lymphangiogenesis under normal and pathologic conditions. ${ }^{10}$ Abundant expression of angiogenic and lymphangiogenic cytokines in tumors HAS bifunctional roles in terms of receptor binding. ${ }^{9,11-14}$ Lymphangiogenic cytokines contribute to the deterioration of immune cells as well as promote the protection of tumor cells and metastasis. ${ }^{14-16}$ Like solid tumors, AML blasts highly express receptors and proangiogenic factors such as VEGF-A, VEGF-C and VEGF-D, ${ }^{17-19}$ implying a direct or indirect function to protect the blasts from anti-cancer drugs. Several cytokines, including VEGF-C and angiopoietin (ANG)-2, are linked to clinical AML outcome. ${ }^{20-22}$ Figure 1 illustrates the interaction of specific cytokines with their receptors, which are expressed in AML and solid tumors. VEGFR-3-expressing natural killer cells in AML, with abundant expression of VEGF-C, are functionally suppressed with low levels of IFN- $\gamma$, suggesting the effects of a lymphangiogenic promoted microenvironment in hematopoietic cells. ${ }^{15}$ The BM, a pivotal organ in AML, is considered to be a secondary organ for mature and homed

Cancer Research Institute, Department of Hematology, Catholic Blood and Marrow Transplantation Center, College of Medicine, The Catholic University of Korea, Seoul, Korea

Correspondence: Professor H-J Kim, Division of Hematology, Department of Internal Medicine, Catholic Blood and Marrow Transplantation Center, Seoul St Mary's Hospital, College of Medicine, The Catholic University of Korea, 505 Banpo 4-dong, Seocho-gu, Seoul 137-701, Korea.

E-mail: cumckim@catholic.ac.kr

Received 23 May 2014; revised 26 August 2014; accepted 21 September 2014 


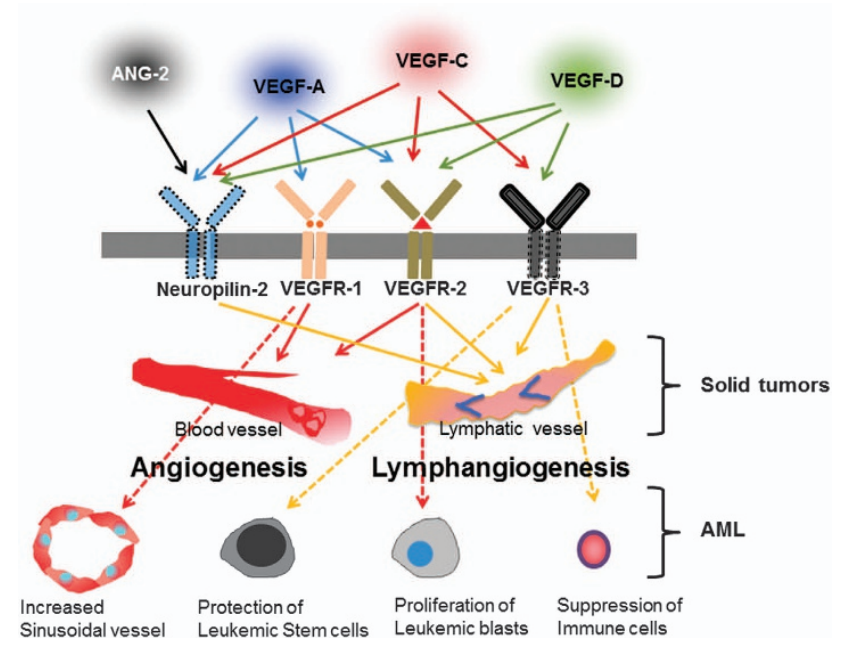

Figure 1 Schematic illustration showing the interaction of specific cytokines and their receptors, which are expressed in AML and solid tumors. Postnatally, blood vessels express VEGFR-1 and VEGFR-2 and the lymphatic endothelium expresses VEGFR-2, VEGFR-3 and Neuropilin-2. On the basis of receptor binding, their signaling causes phosphorylation in specific vessels in tumors. Thus, VEGF-A, VEGF-C, VEGF-D and ANG-2 are important cytokines that promote lymphangiogenesis in solid tumors. In addition, these four (lymph)angiogenic cytokines are abundantly expressed in the $B M$ in AML, indicating their relevance in AML. Solid arrows and dotted arrows indicate solid tumors and AML, respectively.

$\mathrm{CD}^{+}$and $\mathrm{CD}^{+}$cells, as well as a primary lymph organ for lymphogenesis and myelogenesis. ${ }^{23}$ Notably, the BM contains a sinusoidal vessel that permits the circulation of mature blood cells and stem/progenitor cells. Sinusoidal vessels consist of a thin basal lamina and a single layer of endothelial cells without pericytes, ${ }^{24}$ and differ from blood vessels in other organs without possessing the definitive properties of lymphatic vessels. Obscured sinusoidal endothelial cells are supported by myeloid $\mathrm{F} 4 / 80^{+}$cells without lymphatic capillaries and sustain hypoxic conditions in the BM. ${ }^{24,25}$ In solid tumors, hypoxia-related factors, such as hypoxia inducible factor-1, encourage lymphangiogenic promoting conditions. ${ }^{26,27}$ Recent papers revealed the function of lymphangiogenic cytokines in the direct modulation of the immune response in pathologic conditions. ${ }^{28-30}$ The $\mathrm{BM}$ is under the influence of a huge amount of (lymph)angiogenic cytokines of diverse cell types in AML. These (lymph)angiogenic promoting conditions affect all the host cells of AML, including immune cells and stem cells. Although the BM is an organ lacking lymphatic vasculature, it has not been demonstrated whether properties of the sinusoidal endothelium in the BM are restricted to blood vessels, or whether they are similar to those seen in lymphatic vessels in other organs in AML. Thus, we selectively present an overview of the current understanding of the interaction between (lymph)angiogenic cytokines and hematopoietic cells, and provide basic insight into strategies of the advanced lymphatic related factor-targeted therapy in AML.

\section{LYMPHATIC ENDOTHELIAL CELL MARKERS AND LYMPHANGIOGENIC CYTOKINES}

In the past, blood vessel data have been rapidly amassed, whereas lymphatic vessels have been slowly targeted since their pivotal role in tumor biology was revealed. The specific receptor for VEGF-C, VEGFR-3, is a representative marker for the lymphatic endothelium. VEGFR-3 knockout mice die because of cardiac defects and the pivotal role in the lymphatic vasculature with its ligand, VEGF-C. ${ }^{31}$ VEGFR-3 is the first lymphatic marker expressed in lymphatic endothelial cells (LECs), but not in blood endothelial cells, in normal adult tissues. In tumors, VEGFR-3 is abundantly expressed in blood endothelial cells, strongly implying that it contributes to the formation of new blood vessels as a lymphangiogenic factor. ${ }^{32}$ VEGF-C is a representative lymphangiogenic cytokine, and it induces lymphatic vessel enlargement. VEGF- $\mathrm{C}^{-/-}$mice fail to sprout lymphatic vessels, and are rescued by VEGF-D and the VEGF-C/VEGFR-3 axis. ${ }^{7,33,34}$ The VEGF-C/VEGFR-3 axis is a representative pathway in the development of the lymphatic sac and lymphatic vessels in the postnatal stage. ${ }^{35}$ In the BM, Sca- $1^{-}$VEGFR- $3^{+}$VEGFR- $2^{+}$sinusoidal vessels are restricted to the vasculature, supporting $\mathrm{BM}$ angiogenesis and hematopoietic stem cells (HSCs). ${ }^{36}$ The VEGFR- $3^{+}$sinusoidal endothelium expresses VEGF-C through the regulation of cytokines such as fibroblast growth factor (FGF) from blasts, ${ }^{14,37}$ demonstrating the complexity of VEGFR-3 as a marker. Specific LECs initiate Sry-related HMG box (SOX-18) and Prospero homeobox-1 (Prox-1) transcription factors, known as master regulators for lymphatic vessels, ${ }^{38-40}$ in cardinal veins at embryonic day 9.5. Defects in SOX-18 induce lymphatic dysfunction and stimulate Prox-1 expression in lymphatic precursor cells. In 1902, Prox-1 was first proposed by Sabin FR, and was later identified by Wigle JT and Oliver $G{ }^{39}$ as a marker for LECs. Prox-1 knockout mice die at embryonic day 14.5 with an unstable respiratory system. Conditional depletion of Prox-1 converts the cell fate from LECs into blood endothelial cells, ${ }^{41}$ indicating that Prox-1 is a key molecule in lymphatics. Podoplanin is a mucin-type transmembrane glycoprotein that is expressed in both LECs and podocytes. ${ }^{42,43}$ In 2003, Schacht et al. ${ }^{44}$ reported the malformation of lymphatic vessels, but not blood vessels, in Pdpn-knockout mice. These mice died at birth because of respiratory failure. Podoplanin mutant mice display lymphedema and impaired lymphatic vasculature. Podoplanin induces platelet activation through the CLEC-2 receptor, which separates lymphatic vessels from blood vessels. ${ }^{45,46}$ Lymphatic vessel endothelial hyaluronan receptor-1 (Lyve-1) was identified as a lymph-specific receptor by Banerji et al. ${ }^{47}$ in 1999. Although Lyve-1 knockout mice have no abnormal lymphatic phenotypes, ${ }^{48}$ Lyve-1 is expressed in the lymphatic endothelium and macrophages, but not in blood vessels. ${ }^{49,50}$ Recent studies identified new markers for LECs, such as EphB2, FOXC2, ANG-2, Integrin $\alpha 9$, Syk and COUP-TFII, implying pivotal roles for these proteins in the formation of new lymphatic vessels. ${ }^{51-57}$ Another lymphangiogenic cytokine, VEGF-D, is a ligand of VEGFR-3, which induces lymphatic vessel formation and promotes tumor metastasis. ${ }^{33,58}$ 
Neuropilin-2 binds to VEGF-C and VEGF-D and is required for lymphatic vessel development. ${ }^{59,60}$ Proangiogenic cytokines such as platelet-derived growth factor-BB, FGF, hepatocyte growth factor, insulin-like growth factors (IGF) 1 and 2, and VEGF-A, along with the receptor VEGFR-2, also contribute to lymphangiogenesis as direct lymphangiogenic cytokines in changeable pathophysiologic conditions, ${ }^{12,13,61-64}$ demonstrating the dynamic and complicated behavior of angiogenic/ lymphangiogenic cytokines in diseases. As mentioned above, these markers have been used for LECs and lymphangiogenic factors.

\section{BM CELLS AND CONTRIBUTION OF BM CELLS INTO LECS}

The BM, comprised of flexible tissues, consists of heterogeneous cells including HSCs, mesenchymal stromal cells, osteoblasts, osteoclasts, fibroblasts, red blood cells, lymphocytes (natural killer (NK) cells, T cells, B cells), monocytes and DCs along with the extracellular matrix (ECM, fibronectin, collagen). Among these cells, the stem/progenitor cells can differentiate into LECs and macrophages, which contribute to the proliferation of LECs. ${ }^{6,65-67}$ Although it is arguable that stem cells in the BM have plasticity to other cell lineages such as skeletal myoblasts and neural cells, the contribution of BM-derived HSCs and endothelial progenitor cells to blood cells and vessels is commonly accepted. ${ }^{68,69}$ Since the description of endothelial progenitor cells as a therapeutic source by Asahara et $a l,{ }^{69}$ they are commonly thought to treat impaired tissues via neovasculature. ${ }^{70,71}$ Lymphangiogenesis is a more accepted concept than lymphvasculogenesis. ${ }^{72,73}$ However, recent evidence shows that lymphvasculogenesis can occur in the postnatal stage by stem/progenitor cells derived from the $\mathrm{BM},{ }^{6,65,66,74}$ implying that BM-derived cells can function as contributors to LECs. In particular, $\mathrm{CD} 11 \mathrm{~b}^{+}$ macrophages and myelomonocytes are incorporated into new lymphatic vessels in an inflammation-induced cornea model and a tumor model. ${ }^{65,75}$ These papers show the participation of myeloid cells in LEC. CD $133^{+} \mathrm{CD} 34^{+}$VEGFR- $3^{+}$cells, as endothelial cell precursors, have dual functions as lymphatic endothelial progenitor cells and endothelial progenitor cells. ${ }^{66}$ VEGFR $-3^{+} \mathrm{CD}_{14}{ }^{+}$monocytes in circulation also produce the lymphangiogenic cytokine VEGF-C, which may serve lymphatic endothelial progenitor cells from hematopoietic cells. ${ }^{66,76}$ To note, $\mathrm{CD}_{11 \mathrm{~b}^{+}}$and $\mathrm{Flt}^{+}$cells can differentiate into cells of several lineages as well as LECs. $\mathrm{CD}_{11} \mathrm{~b}^{+} \mathrm{B} 220^{+}$cells differentiate into B lymphocytes, and $\mathrm{Flt}^{+}$cells can function as progenitor cells for NK cells. ${ }^{77}$ Cells in the hematopoietic system, in particular macrophages and monocytes, have the plasticity to form LECs and cells of other lineages in pathologic situations. As described above, myeloid cells strongly contribute to lymphangiogenesis via direct or indirect mechanisms, as well as to angiogenesis in pathophysiological conditions. However, the relationship between BM cells and LECs in the extramedullary organ, as well as to the BM of hematologic malignancies, remains to be investigated.

\section{VEGF FAMILY IN AML}

The human VEGF family consists of VEGF-A, VEGF-B, VEGF-C, VEGF-D and placental growth factor. There are three VEGF receptor tyrosine kinases: VGFR-1, VEGFR-2 and VEGFR-3. VEGF-A has several isoforms, known as VEGF 110 , $V E_{121}, V \mathrm{VGF}_{145}, \mathrm{VEGF}_{146}, \mathrm{VEGF}_{148}, \mathrm{VEGF}_{165}, \mathrm{VEGF}_{167}$, $V_{E G F} 183, V E_{186}, V_{18 F}$ and $V_{1 E G F}$, and their functions are based on the binding to the extracellular matrix. ${ }^{78}$ The most important factors in AML are VEGF-A and VEGF-C, which are expressed on BM cells in AML. VEGF was isolated in the HL-60 myeloid leukemia cell line, and its AML expression was first reported by Fiedler et al. ${ }^{17,79}$ Increased microvessel density is associated with angiogenic factors such as VEGF and is seen in the BM of AML patients. ${ }^{1-3}$ Most AML BM cells greatly increase expression of VEGFs and their receptors, depending on factors such as AML subtype (i.e., $t(15 ; 17)$ or $t$ $(8 ; 21)$ AML), polymorphism score and vascular morphology in remission status. ${ }^{80-83}$ In particular, VEGFR-2 is constitutively phosphorylated and is relocated intracellularly to the nucleus from the surface in leukemia, $t(8 ; 21)$ and MLL, but not in other cytogenetic groups. ${ }^{83,84}$ In addition, the proliferation of AML is blocked by anti-VEGFR-2 drugs via the inhibition of VEGF/VEGFR-2 phosphorylation. This suggests that the VEGF signal is dependent on the cytogenetic subgroup, and that therapy using a VEGF inhibitor should be performed based on individual characteristics of AML. VEGF in AML cells can act via autocrine and paracrine signaling. The activated VEGFA/ VEGFR-2 axis regulates blast survival and growth by internal loops via an intracellular receptor without secretion. This loop is not dependent on cell density, and exogenous neutralizing antibodies cannot arrest the proliferation of blasts by this autonomous machinery. External autocrine loops are also involved in preventing blast survival and releasing VEGF-A from the blasts (autocrine), activating VEGF receptors on AML blasts which bind to VEGF from other stromal cells (paracrine). ${ }^{81,84}$ Like VEGFR-2, VEGFR-3 also has two types of receptors for activation, an intracellular receptor and a surface receptor. Internalized VEGFR-3, which can be relocated into the cytoplasm by ephrin-B2, occurs in lymphangiogenesis, ${ }^{85}$ implying that VEGF receptors act via internal loops. Autocrine signaling in AML also maintains the survival of blasts. ${ }^{18}$ Simultaneously, VEGF-C from endothelial cells can conserve VEGFR-3 ${ }^{+}$blasts after chemotherapy via paracrine signaling. ${ }^{14}$ VEGF-C-releasing endothelial cells and blasts can affect all the hematopoietic cells in the BM as well as VEGFR- $3^{+}$blasts. VEGF-C is abundantly expressed on BM in AML with its receptor VEGFR-3, and these molecules support leukemic cell proliferation against chemotherapy. ${ }^{14,18}$ Both factors, VEGF-A and VEGF-C, contribute to the proliferation of the lymphatic endothelium and tumors in a tumor model, ${ }^{12,14}$ suggesting that they function as (lymph)angiogenic factors. Direct interactions (juxtacrine loops) between blasts and stromal cells are important for blast survival in AML BM. ${ }^{86}$ These proteins have a clinical correlation in AML. Patients with VEGF-A and VEGF$\mathrm{C}$ overexpression showed reduced survival and poor prognosis. ${ }^{14,22,87,88}$ It is necessary to further address whether 
proangiogenic VEGF in the BM can affect extramedullary lymphatics and immune cells and act as a (lymph)angiogenic stimulator via endocrine signaling in AML, which is likely for solid tumors.

\section{OTHER (LYMPH)ANGIOGENIC CYTOKINES AND AML}

AML is a heterogeneous blood disorder, which has complex gene and cytokine expression. Like solid tumors, AML presents with overexpression of angiogenic cytokines, which can convert their function into (lymph)angiogenic processing. IGF I promotes AML blast survival via the phosphoinositide 3-kinase/Akt pathway, ${ }^{89}$ and IGF binding protein 2 is expressed on AML blast and HSCs. This molecule supports blast migration and promotes survival in an autocrine manner, along with the differentiation of osteoclasts, ${ }^{90,91}$ suggesting an association with the BM. Hepatocyte growth factor is an angiogenic cytokine and a pivotal element in AML blast and cell lines. Its receptor c-MET is also activated in AML. IGF, hepatocyte growth factor and FGF, which are not VEGF family members, function as (lymph)angiogenic factors in various solid tumors, predicting the lymphatic potential in AML. FGF influences myeloid progenitor cells as well as HSCs in survival. In particular, the MLL-ELL oncoprotein, also known as MLL fusion protein, strongly induces FGF in AML by autocrine stimulation. ${ }^{37,92}$ As mentioned above, almost all lymphangiogenic and angiogenic cytokines have an important role in conserving leukemic cells, and these cytokines are autonomously released from blasts in AML. These cytokines have bifunctional roles to form vasculature in solid tumors. Although the BM has no lymphatic capillaries in AML, many lymphangiogenic cytokines influence hematopoietic cells in the BM microenvironment.

\section{RECIPROCAL INTERACTION BETWEEN (LYMPH) ANGIOGENIC FACTORS AND IMMUNE CELLS}

Traditionally, the lymphatic system has been considered a transportation system for tissue fluid homeostasis and immune cells, including DCs and macrophages. ${ }^{93}$ It is known that lymphangiogenesis and immune cell suppression are involved in cancer. However, little is known about how lymphangiogenic factors affect immunity in pathological conditions. Increasing evidence has shown that the lymphatic endothelium and cytokines from LECs can regulate immune cell function. Podgrabinska $S$ et al. report that the lymphatic endothelium directly suppresses DC function under inflammatory conditions, indicating that LECs are active participants in immune cell function. ${ }^{28}$ Lund et al. ${ }^{30}$ addressed the protection from antitumor immunity in melanoma afforded by VEGF-C. VEGF-C induces the immune tolerance of tumor antigenspecific $\mathrm{CD}^{+} \mathrm{T}$ cells. The escape of tumors from the immune response occurs by lymphatic and interstitial flow. ${ }^{94}$ In a maternal-fetal interface, VEGF-C induces NK cell tolerance with a $\mathrm{CD} 56^{\text {high }} \mathrm{CD} 16^{\mathrm{dim}}$ phenotype in the uterus. ${ }^{95}$ Recent papers address the direct communication between the lymphatic endothelium or lymphangiogenic factors and immune cell function. VEGF-C can recruit VEGFR-3 ${ }^{+}$ tumor-associated macrophages, which simultaneously encourage immune suppression and blast protection from chemotherapy. ${ }^{14,96,97}$ Krebs et al. ${ }^{98}$ provide evidence that VEGF-C/VEGFR-3 signaling is also crucial for active, innate and adaptive immune responses as well as neovasculature in lung injury. Under high VEGF-C levels, high VEGFR- $3^{+}$NK cells in AML display lower levels of cytotoxicity in response to low levels of IFN- $\gamma$ than VEGFR-3- ${ }^{-}$NK cells. In mouse experiments, KLRG1+/CX3CR1-GFP+ NK cells, which reside in VEGFR-3+ sinusoids, have lower killing potential than NK cells in the parenchyma, ${ }^{15,99}$ suggesting a relationship between VEGFR-3 expression and NK cell function. IFN- $\gamma$ is a main cytokine that attacks tumor cells by immune cells such as $\mathrm{T}$ and NK cells. IFN- $\gamma$ is known as an anti-angiogenic or lymphangiogenic factor in the tumor microenvironment and in vitro experiments. ${ }^{50,100,101}$ It can be inferred that opposing regulation exists between IFN- $\gamma$ releasing immune cells and neo lymphangiogenesis. Other immune cells and mast cells (MCs) are influenced by the lymphatic endothelium and are located near vascular and lymphatic vessels. ${ }^{29}$ The function of MCs has been restricted to the allergic response. However, their importance in innate and adaptive immunity was magnified in pathogen infection and in immunotherapy in tumors. ${ }^{102,103}$ AML, which is a diagnosis of systemic mastocytosis, is not thought to be of mast cell lineage. Although there is no detection of MCs in de novo AML, MCs appear at the relapse stage, which highly stimulate the lymphangiogenic conditions in $\mathrm{t}(8 ; 21)(\mathrm{q} 22 ; \mathrm{q} 22)$ patients or AML1/ETO-positive AMLs after HSCT. ${ }^{104,105}$ Whether high levels of lymphangiogenic factors lead to the dysfunction of MCs with a VEGFR- $3^{+}$phenotype, unbalanced immunity, and the induction of relapse status remains to be investigated. Furthermore, the feasibility of VEGFR- $3^{+}$MCs as predictors of relapse in AML needs to be examined. On the other hand, Syk ${ }^{+}$leukocytes have been shown to induce lymphangiogenesis, but not endothelial progenitor cells. ${ }^{106}$ This shows the capacity of mature hematopoietic cells to control lymphangiogenesis. B cells and CD11b +/GR1+ macrophages produce VEGF-A, C and D in the periphery under inflammatory conditions. ${ }^{67,107}$ Murakami et al. ${ }^{108}$, using Vegfr $1 \mathrm{tk}^{-1-}$ mice, reported that VEGF-A recruited BM-derived macrophages via the activation of VEGFR-1 on macrophages in subcutaneous tissues. Cursiefen et al. ${ }^{109}$ also showed that VEGF-A stimulates lymphangiogenesis and macrophage recruitment, using a VEGF trap in an inflammatory corneal model. These papers demonstrated that VEGF-A induces the mobilization of monocytes, which then leads to the production of VEGF-C and D in differentiated monocytes. Although VEGF-A stimulation initiates angiogenesis, the function of VEGF-A as a lymphangiogenic cytokine has gradually been revealed in pathological conditions. A new challenge for lymphatics is to understand how they act as active immunosuppressants and function as regulators in tumor microenvironments. ${ }^{110,111}$ Once AML is induced, VEGFR-3 and other LEC markers such as Prox-1, Lyve-1 and podoplanin are 
highly expressed in NK cells as well as in BM- and PB-derived mononuclear cells. These markers are generally restricted to lymphangiogenic factors in the postnatal stage; hence, abundant expression suggests the relevance of increased lymphangiogenic factors to immune cells in the progression of AML. ${ }^{15}$

\section{(LYMPH)ANGIOGENIC CYTOKINES IN THE BM NICHE}

Hematopoietic processing occurs in the BM. BM structure is divided into two main microenvironments. One is the osteoblast niche, which is localized in the inner surface of the bone, lined with osteoblasts from mesenchymal precursors. It serves as a reservoir for long-time HSC with hypoxic conditions. The other is the vascular niche, consisting of sinusoidal vessels that exit the BM and circulate blood cells. In both regions, (lymph)angiogenic cytokines are produced by hematopoietic cells. Cells of osteolineage and reticular perivascular cells are regarded as the major cells in the HSC niches that maintain HSCs. VEGF-A and VEGF-C are necessary factors for HSC retention. Ishikawa et al. ${ }^{112}$ reported that leukemic stem cells homed in the endosteal region after chemotherapy. Because resistant leukemic blasts require the protective niche to relapse, VEGF-A from mesenchymal stromal cells, sinusoidal endothelium and osteoblasts in the endosteal niche may be involved in AML leukemic stem cell niche-associated relapses. However, the interaction between the niche composition and hematopoietic cells should be examined to provide more detailed evidence in a syngeneic mouse model, which can recapitulate the physiologic hematopoiesis in the niche. $\mathrm{CD} 146^{+}$subendothelial cells, which reside in sinusoidal vessels, produce ANG-1. ANG-1 is a key molecule for HSC quiescence in the BM niche, with its receptor Tie-2. ${ }^{13,114}$ The BM vascular niche was phenotypically and functionally addressed by Hooper et al. ${ }^{36}$ They found that the regeneration of sinusoidal endothelial cells by VEGFR-2 is critical to HSC engraftment, regardless of the osteoblastic niche conditions. In addition, the importance of sinusoidal endothelial cells in reconstructing transplanted $\mathrm{BM}$ cells in the $\mathrm{BM}$ after irradiation was addressed. Further experimentation with the sinusoidal vessel is needed to investigate whether it is a bifacial regulator in AML, functioning both as a routine exit from the BM and by regulating other immune or leukemic stem cells as enhancers for (lymph)angiogenic factors. By reintroducing the Fanconi anemia-related gene (Fang) by injection of normal mesenchymal stromal cell into Fancg ${ }^{-/-}$ mice, Li et al. ${ }^{115}$ showed that mesenchymal stromal cells are a crucial factor in maintaining HSC. Kwon et al. ${ }^{116}$ also first reported a correlation between vascular deterioration and HSC frequency in a genetically manipulated mouse model. Tumor (lymph)angiogenesis is activated and closely involved in disease-free survival in solid tumors. In particular, VEGF$\mathrm{C}$ is a representative predictor for reduced survival via lymph node metastasis in melanoma, breast cancer and lung cancer. ${ }^{117-119}$ Like solid tumors, AML is exposed to (lymph)angiogenic cytokines. VEGF-C and VEGF-A in the $\mathrm{BM}$ are representative cytokines for the prediction of poor outcome and for the definition of AML subgroups. ${ }^{22,120}$ Functional evidence in blast proliferation and survival, as well as the expression of VEGF-C and VEGF-A in AML blasts, have been shown by many reports. ${ }^{14,121,122}$ Both cytokines stimulate the migration of endothelial cells. When AML is induced, expanded BM endothelial cells release leukemic growth factors, including granulocytemacrophage colony stimulating factor and interleukin-6. 17,19 Osteopontin (OPN), which is known as early T-lymphocyte activation- 1 and was first identified in osteoblasts in 1986, is released by osteoblasts and hematopoietic cells in the BM. Overexpressed OPN, as a lymphangiogenic factor, promotes metastasis via the integrin $\alpha 9$ pathway. OPN is also a prognostic indicator for survival in AML. ${ }^{123,124}$ Although little is known about the potential reciprocal interaction between hematopoietic cells, including leukemic stem cells, immune cells and the BM niche, there is no controversy regarding the importance of the BM niche in AML. Figure 2 presents the BM niche activity in AML. Previous knowledge in AML can lead to advanced therapeutic protocols through understanding the biological activity in the leukemic niche.

\section{PHARMACOLOGIC PERSPECTIVES OF AML TREATMENT}

Many anti-angiogenic drugs have been used to treat AML. Because of their broad spectrum of use, from basic science

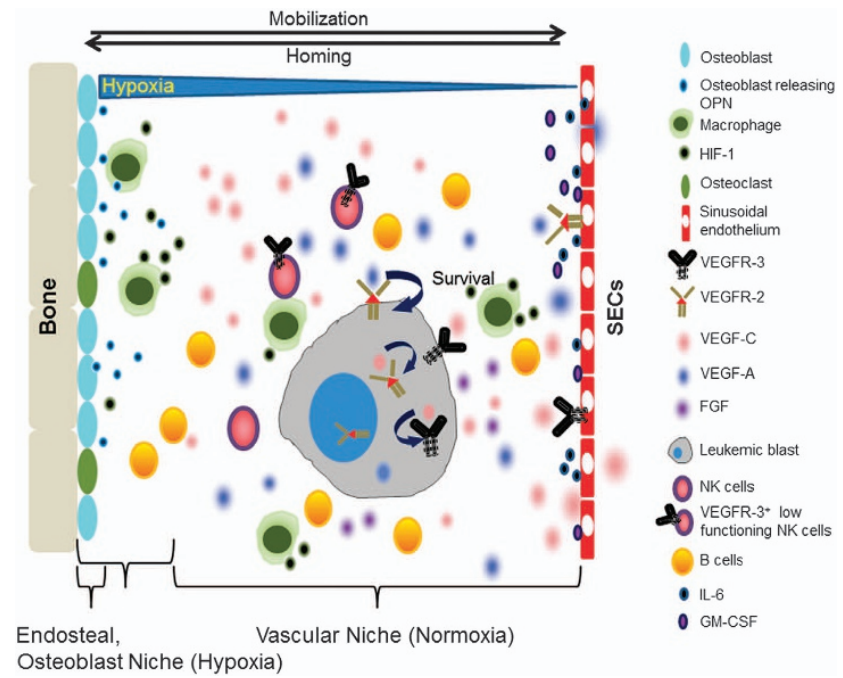

Figure 2 Schematic illustration showing the dynamic BM niche in AML. Abundant expression of lymphangiogenic cytokines, including VEGF-C, VEGF-A, OPN and their receptors, VEGFR-3 and VEGFR-2, are found in BM cells. Under high levels of (lymph)angiogenic cytokines, hematopoietic cells including leukemic stem cells and immune cells are affected, resulting in the dysfunction of immune cells and protection of leukemic stem cells. Abbreviations: OPN, Osteopontin; HIF-1, Hypoxia inducible factor-1; SECs, Sinusoidal endothelial cells; VEGFR-3, Vascular endothelial growth factor receptor-3; VEGFR-2, Vascular endothelial growth factor receptor-2; VEGF-C, Vascular endothelial growth factor-C; VEGF-A, Vascular endothelial growth factor-A; FGF, Fibroblast growth factor; NK cells, Natural killer cells; GM-CSF, Granulocyte macrophage-colony stimulating factor. 
to clinical applications, anti-angiogenic drugs including bevacizumab (Avastin) and SU11248 (sunitinib) have been implemented in AML as well as in solid tumors. ${ }^{125-127}$ Bevacizumab is a monoclonal antibody against VEGF-A, and a representative inhibitor of angiogenesis. Although combination therapy has the limitations of dose-limiting toxicity, when chemoreagents and PTK787/ZK222584/ Vatalanib (PTK) are simultaneously applied most of the target molecules, including Bevacizumab and PTK, show higher susceptibility rates in combination therapy with imatinib than in monotherapy for complete remission of AML. PTK787/ZK222584 is a tyrosine kinase inhibitor that binds to the ATP-binding sites of VEGF receptors. ${ }^{128,129}$ The small molecules SU5416 and SU11248 inhibit VEGF receptors and are used in refractory AML. ${ }^{127,130}$ Recently, monoclonal antibodies and small molecules targeting VEGF-C/ VEGFR-3 have progressed in Phase I clinical trials for solid tumors. ${ }^{131-133}$ On the basis of animal experiments, molecules targeting VEGF signaling in AML have implied that inhibiting lymphangiogenic signaling can block the recurrence of leukemic blasts. In particular, inhibitors targeting VEGFR-3, including monoclonal antibody Hf4-3C5, have been developed and are in phase I clinical trials, numbered NCT01288989. ${ }^{131}$ Other small molecules targeting VEGFR, such as Pazopanib, Axitinib and Regorafenib, were reported to restrict both VEGFR-3 and VEGFR-2 or Tie2 inhibition and have been used in solid tumors but not yet in AML. ${ }^{134-136}$ The next-generation strategy, dual functional reagents which can function as anti-angiogenic factors and immunomodulators, such as pomalidomide (originally CC-4047 or 3-amino-thalidomide), needs to be elicited for the advanced treatment of AML. ${ }^{137,138}$ A therapeutic value for IGF-I was confirmed using the NVP-AEW541 inhibitor, which resulted in decreased CD31. ${ }^{139}$ The inhibition of the hepatocyte growth factor receptor MET by crizotinib failed to maintain a blast-free condition unless applied with dual inhibition of FGFR1. ${ }^{140}$ The anti-angiopoietin peptibody AMG-386, which inhibits ANG1 and ANG2 with the Tie-2 receptor, is under clinical phase II trials (NCT01290263) for use in a variety of solid tumors, but not for leukemia. ${ }^{141}$ All cytokines mentioned above have the potential to suppress lymphangiogenic factors as well as angiogenic factors toward AML blasts and tumor environment in the BM. Most therapeutic agents, known as anti-angiogenic drugs, may be applied with other reagents such as $\mathrm{HDAC}$ and $\mathrm{mTOR}$ inhibitors in AML treatment. Figure 3 summarizes the potential targets and inhibitors in AML.

\section{CONCLUSION}

In this review, we noted the (lymph)angiogenic influences on hematopoietic cells involved in AML. On the basis of conditions in the tumor microenvironment, (lymph)angiogenic cytokines alter their expression and interaction in cells in the BM niche, protecting leukemic cells. (Lymph) angiogenesis is a common process in tumors. Similar to solid tumors, AML is also closely associated with proangiogenic and lymphangiogenic cytokines in the BM. Sinusoidal vessels in the BM have unusual properties and are different from other vasculatures, including blood vessels and lymphatic vessels. Once leukemia occurs, the BM has a dynamic behavior with leukemia cells and immune cells in the BM niche. Moreover, lymphatic-specific marker proteins such as Prox-1, podoplanin and VEGFR-3, as well as (lymph) angiogenic cytokines including VEGF-C and VEGF-A, are highly increased in BM- and in PB-MNCs. The VEGF and non-VEGF cytokines are important, and are altered to affect all cell types in AML BM. In particular, immune cells such as macrophages, as well as stem/progenitor cells, can contribute to lymphatic-promoting conditions. The pivotal roles of these increased lymphangiogenic factors in the BM niche in AML need to be determined. Because the concept of (lymph) angiogenesis is not foreign to hematologic malignancies and solid tumors, further studies may be needed to elicit the vivo machinery linking immune cells, leukemic stem cells and lymphangiogenic function in situ. Although it showed the ambilaterality of angiogenic and lymphangiogenic cross talk, the aberrant expression of lymphangiogenic factors in AML is also a feature of pathophysiologic conditions. Lymphangiogenic related study therefore has value as a therapeutic solution to treat AML in the future. New therapeutic strategies focusing on the modulation of lymphangiogenic factors may lead to advanced treatment options by eliciting environmental changes in AML.

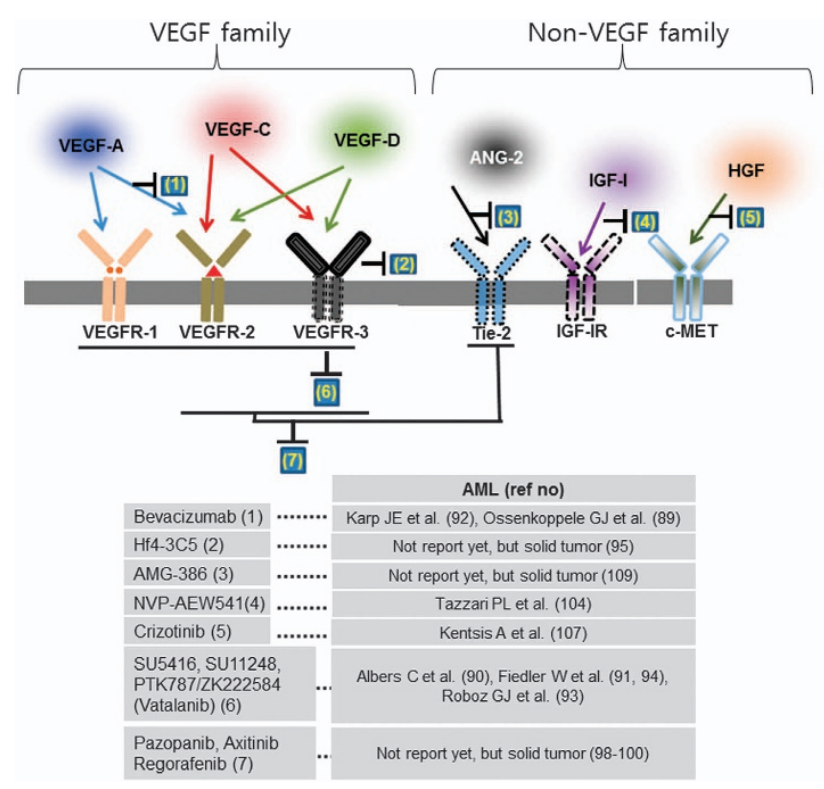

Figure 3 Potential targets and inhibitors for (lymph)angiogenic factors in AML. As target molecules involved in lymphangiogenesis, several factors have been applied in clinical studies. AML focused agents typically target dual or multiple protein kinases, and then chemotherapy combined trials with inhibitors to effectively inhibit AML blasts. 


\section{CONFLICT OF INTEREST}

The authors declare no conflict of interest.

\section{ACKNOWLEDGEMENTS}

We are grateful to Donghyun Curt Kim for proofreading the manuscript. This study is fully supported by the Committee for Life, the Archdiocese of Seoul, and Republic of Korea.

1 Padro T, Ruiz S, Bieker R, Burger H, Steins M, Kienast J et al. Increased angiogenesis in the bone marrow of patients with acute myeloid leukemia. Blood 2000; 95: 2637-2644.

2 Hussong JW, Rodgers GM, Shami PJ. Evidence of increased angiogenesis in patients with acute myeloid leukemia. Blood 2000; 95: 309-313.

3 de Bont ES, Rosati S, Jacobs S, Kamps WA, Vellenga E. Increased bone marrow vascularization in patients with acute myeloid leukaemia: A possible role for vascular endothelial growth factor. $\mathrm{Br} J$ Haematol 2001; 113: 296-304.

4 Folkman J. Tumor angiogenesis: Therapeutic implications. N Engl J Med 1971; 285: 1182-1186.

5 Srinivasan RS, Dillard ME, Lagutin OV, Lin FJ, Tsai S, Tsai MJ et al. Lineage tracing demonstrates the venous origin of the mammalian lymphatic vasculature. Genes Dev. 2007; 21: 2422-2432.

6 Lee JY, Park C, Cho YP, Lee E, Kim H, Kim P et al. Podoplanin-expressing cells derived from bone marrow play a crucial role in postnatal lymphatic neovascularization. Circulation 2010; 122: 1413-1425.

7 Karkkainen MJ, Haiko P, Sainio K, Partanen J, Taipale J, Petrova TV et al. Vascular endothelial growth factor $c$ is required for sprouting of the first lymphatic vessels from embryonic veins. Nat Immunol 2004; 5: 74-80.

8 Alitalo K, Tammela T, Petrova TV. Lymphangiogenesis in development and human disease. Nature 2005; 438: 946-953.

9 Adams RH, Alitalo K. Molecular regulation of angiogenesis and lymphangiogenesis. Nat Rev Mol Cell Biol 2007; 8: 464-478.

10 Tammela T, Alitalo K. Lymphangiogenesis: Molecular mechanisms and future promise. Cell 2010; 140: 460-476.

11 Joukov V, Pajusola K, Kaipainen A, Chilov D, Lahtinen I, Kukk E et al. A novel vascular endothelial growth factor, VEGF-C, is a ligand for the FLT4 (VEGFR-3) and KDR (VEGFR-2) receptor tyrosine kinases. EMBO J 1996; 15: 1751.

12 Hirakawa S, Kodama S, Kunstfeld R, Kajiya K, Brown LF, Detmar M. VEGF-A induces tumor and sentinel lymph node lymphangiogenesis and promotes lymphatic metastasis. J Exp Med 2005; 201: 1089-1099.

13 Chang LK, Garcia-Cardena G, Farnebo F, Fannon M, Chen EJ, Butterfield $\mathrm{C}$ et al. Dose-dependent response of FGF-2 for lymphangiogenesis. Proc Natl Acad Sci USA 2004; 101: 11658-11663.

14 Dias S, Choy M, Alitalo K, Rafii S. Vascular endothelial growth factor (VEGF)-c signaling through FLT-4 (VEGFR-3) mediates leukemic cell proliferation, survival, and resistance to chemotherapy. Blood 2002; 99 . 2179-2184.

15 Lee JY, Park S, Kim DC, Yoon JH, Shin SH, Min WS et al. A VEGFR-3 antagonist increases IFN-gamma expression on low functioning nk cells in acute myeloid leukemia. J Clin Immunol 2013; 33: 826-837.

16 Skobe M, Hawighorst T, Jackson DG, Prevo R, Janes L, Velasco P et al. Induction of tumor lymphangiogenesis by VEGF-C promotes breast cancer metastasis. Nat Med 2001; 7: 192-198.

17 Fiedler W, Graeven U, Ergun S, Verago S, Kilic N, Stockschlader M et al. Vascular endothelial growth factor, a possible paracrine growth factor in human acute myeloid leukemia. Blood 1997; 89: 1870-1875.

18 Fielder W, Graeven U, Ergun S, Verago S, Kilic N, Stockschlader M et al. Expression of FLT4 and its ligand VEGF-C in acute myeloid leukemia. Leukemia 1997; 11: 1234-1237.

19 Bellamy WT, Richter L, Frutiger Y, Grogan TM. Expression of vascular endothelial growth factor and its receptors in hematopoietic malignancies. Cancer Res 1999; 59: 728-733.

20 Hou HA, Chou WC, Lin LI, Tang JL, Tseng MH, Huang CF et al. Expression of angiopoietins and vascular endothelial growth factors and their clinical significance in acute myeloid leukemia. Leuk Res 2008; 32: 904-912.

21 Loges S, Heil G, Bruweleit M, Schoder V, Butzal M. Fischer U et al. Analysis of concerted expression of angiogenic growth factors in acute myeloid leukemia: Expression of angiopoietin-2 represents an independent prognostic factor for overall survival. J Clin Oncol 2005; 23: 1109-1117.

22 de Jonge HJ, Valk PJ, Veeger NJ, ter Elst A, den Boer ML, Cloos J et al. High VEGFC expression is associated with unique gene expression profiles and predicts adverse prognosis in pediatric and adult acute myeloid leukemia. Blood 2010; 116: 1747-1754.

23 Di Rosa F, Pabst R. The bone marrow: A nest for migratory memory t cells. Trends Immunol 2005; 26: 360-366.

24 Kopp HG, Avecilla ST, Hooper AT, Shmelkov SV, Ramos CA, Zhang F et al. Tie2 activation contributes to hemangiogenic regeneration after myelosuppression. Blood 2005; 106: 505-513.

25 Sapoznikov A, Pewzner-Jung Y, Kalchenko V, Krauthgamer R, Shachar I, Jung S. Perivascular clusters of dendritic cells provide critical survival signals to b cells in bone marrow niches. Nat Immunol 2008; 9 : 388-395.

26 Schito L, Rey S, Tafani M, Zhang H, Wong CC, Russo A et al. Hypoxia-inducible factor 1-dependent expression of platelet-derived growth factor $b$ promotes lymphatic metastasis of hypoxic breast cancer cells. Proc Natl Acad Sci USA 2012; 109: E2707-E2716.

27 Schoppmann SF, Fenzl A, Schindl M, Bachleitner-Hofmann T, Nagy K, Gnant $\mathrm{M}$ et al. Hypoxia inducible factor-1alpha correlates with VEGF-C expression and lymphangiogenesis in breast cancer. Breast Cancer res Treat 2006; 99: 135-141.

28 Podgrabinska S, Kamalu O, Mayer L, Shimaoka M, Snoeck H, Randolph GJ et al. Inflamed lymphatic endothelium suppresses dendritic cell maturation and function via MAC-1/ICAM-1-dependent mechanism. J Immunol 2009; 183: 1767-1779.

29 Kunder CA, St John AL, Abraham SN. Mast cell modulation of the vascular and lymphatic endothelium. Blood 2011; 118: 5383-5393.

30 Lund AW, Duraes FV, Hirosue S, Raghavan VR, Nembrini C, Thomas SN et al. VEGF-C promotes immune tolerance in B16 melanomas and cross-presentation of tumor antigen by lymph node lymphatics. Cell Rep 2012; 1: 191-199.

31 Dumont DJ, Jussila L, Taipale J, Lymboussaki A, Mustonen T, Pajusola K et al. Cardiovascular failure in mouse embryos deficient in VEGFR-3. Science 1998; 282: 946-949.

32 Clarijs R, Schalkwijk L, Hofmann UB, Ruiter DJ, de Waal RM. Induction of vascular endothelial growth factor receptor-3 expression on tumor microvasculature as a new progression marker in human cutaneous melanoma. Cancer Res 2002; 62: 7059-7065.

33 Veikkola T, Jussila L, Makinen T, Karpanen T, Jeltsch M, Petrova TV et al. Signalling via vascular endothelial growth factor receptor-3 is sufficient for lymphangiogenesis in transgenic mice. EMBO J 2001; 20: 1223-1231.

34 Jeltsch M, Kaipainen A, Joukov V, Meng X, Lakso M, Rauvala $\mathrm{H}$ et al. Hyperplasia of lymphatic vessels in VEGF-C transgenic mice. Science 1997; 276: 1423-1425.

35 Kaipainen A, Korhonen J, Mustonen T, van Hinsbergh VW, Fang GH, Dumont $\mathrm{D}$ et al. Expression of the fms-like tyrosine kinase 4 gene becomes restricted to lymphatic endothelium during development. Proc Natl Acad Sci USA 1995; 92: 3566-3570.

36 Hooper AT, Butler JM, Nolan DJ, Kranz A, lida K, Kobayashi M et al. Engraftment and reconstitution of hematopoiesis is dependent on VEGFR2-mediated regeneration of sinusoidal endothelial cells. Cell Stem Cell 2009; 4: 263-274.

37 Bieker R, Padro T, Kramer J, Steins M, Kessler T, Retzlaff S et al. Overexpression of basic fibroblast growth factor and autocrine stimulation in acute myeloid leukemia. Cancer Res 2003; 63: 7241-7246.

38 Francois M, Caprini A, Hosking B, Orsenigo F, Wilhelm D, Browne C et al. Sox 18 induces development of the lymphatic vasculature in mice. Nature 2008; 456: 643-647.

39 Wigle JT, Oliver G. Proxl function is required for the development of the murine lymphatic system. Cell 1999; 98: 769-778.

40 Hong YK, Harvey N, Noh YH, Schacht V, Hirakawa S, Detmar M et al. Prox1 is a master control gene in the program specifying lymphatic endothelial cell fate. Dev Dyn 2002; 225: 351-357.

41 Johnson NC, Dillard ME, Baluk P, McDonald DM, Harvey NL, Frase SL et al. Lymphatic endothelial cell identity is reversible and its maintenance requires prox1 activity. Genes Dev 2008; 22: 3282-3291.

42 Breiteneder-Geleff S, Soleiman A, Kowalski H, Horvat R, Amann G, Kriehuber $\mathrm{E}$ et al. Angiosarcomas express mixed endothelial phenotypes of 
blood and lymphatic capillaries: Podoplanin as a specific marker for lymphatic endothelium. Am J Pathol 1999; 154: 385-394.

43 Matsui K, Breitender-Geleff S, Soleiman A, Kowalski H, Kerjaschki D. Podoplanin a novel 43-kda membrane protein, controls the shape of podocytes. Nephrol Dial Transplant 1999; 14(Suppl 1): 9-11.

44 Schacht V, Ramirez MI, Hong YK, Hirakawa S, Feng D, Harvey N et al. T1alpha/podoplanin deficiency disrupts normal lymphatic vasculature formation and causes lymphedema. EMBO J 2003; 22: 3546-3556.

45 Bertozzi CC, Schmaier AA, Mericko P, Hess PR, Zou Z, Chen M et al. Platelets regulate lymphatic vascular development through CLEC-2SLP-76 signaling. Blood 2010; 116: 661-670.

46 Kato Y, Fujita N, Kunita A, Sato S, Kaneko M, Osawa M et al. Molecular identification of aggrus/Tlalpha as a platelet aggregation-inducing factor expressed in colorectal tumors. J Biol Chem 2003; 278: 51599-51605.

47 Banerji S, Ni J, Wang SX, Clasper S, Su J, Tammi R et al. Lyve-1, a new homologue of the CD44 glycoprotein, is a lymph-specific receptor for hyaluronan. J Cell Biol 1999; 144: 789-801.

48 Gale NW, Prevo R, Espinosa J, Ferguson DJ, Dominguez MG, Yancopoulos GD et al. Normal lymphatic development and function in mice deficient for the Iymphatic hyaluronan receptor LYVE-1. Mol Cell Biol 2007; 27 595-604.

$49 \mathrm{Xu} \mathrm{H}$, Chen M, Reid DM, Forrester JV. LYVE-1-positive macrophages are present in normal murine eyes. Invest Ohthalmol Vis Sci 2007; 48: 2162-2171.

50 Kataru RP, Kim H, Jang C, Choi DK, Koh BI, Kim M et al. T lymphocytes negatively regulate lymph node lymphatic vessel formation. Immunity 2011; 34: 96-107.

51 Makinen T, Adams RH, Bailey J, Lu Q, Ziemiecki A, Alitalo K et al. PDZ interaction site in ephrinB2 is required for the remodeling of lymphatic vasculature. Genes Dev 2005; 19: 397-410.

52 Petrova TV, Karpanen T, Norrmen C, Mellor R, Tamakoshi T, Finegold D et al. Defective valves and abnormal mural cell recruitment underlie lymphatic vascular failure in lymphedema distichiasis. Nat Med 2004; 10: 974-981.

53 Gale NW, Thurston G, Hackett SF, Renard R, Wang Q, McClain J et al. Angiopoietin-2 is required for postnatal angiogenesis and lymphatic patterning, and only the latter role is rescued by angiopoietin-1. Devel Cell 2002; 3: 411-423.

54 Huang XZ, Wu JF, Ferrando R, Lee JH, Wang YL, Farese RV et al. Fatal bilateral chylothorax in mice lacking the integrin alpha9beta1. Mol Cell Biol 2000; 20: 5208-5215.

55 Abtahian F, Guerriero A, Sebzda E, Lu MM, Zhou R, Mocsai A et al. Regulation of blood and lymphatic vascular separation by signaling proteins SLP-76 and SYK. Science 2003; 299: 247-251.

56 Srinivasan RS, Geng X, Yang Y, Wang Y, Mukatira S, Studer M et al. The nuclear hormone receptor COUP-TFII is required for the initiation and early maintenance of prox 1 expression in lymphatic endothelial cells. Genes Dev 2010; 24: 696-707.

57 Lee S, Kang J, Yoo J, Ganesan SK, Cook SC, Aguilar B et al. Prox 1 physically and functionally interacts with COUP-TFII to specify lymphatic endothelial cell fate. Blood 2009; 113: 1856-1859.

58 Stacker SA, Caesar C, Baldwin ME, Thornton GE, Williams RA, Prevo R et al. VEGF-D promotes the metastatic spread of tumor cells via the lymphatics. Nat Med 2001; 7: 186-191.

59 Karkkainen MJ, Saaristo A, Jussila L, Karila KA, Lawrence EC, Pajusola K et al. A model for gene therapy of human hereditary lymphedema. Proc Natl Acad Sci USA 2001; 98: 12677-12682.

60 Yuan L, Moyon D, Pardanaud L, Breant C, Karkkainen MJ, Alitalo K et al. Abnormal lymphatic vessel development in neuropilin 2 mutant mice. Development 2002; 129: 4797-4806.

61 Cao R, Bjorndahl MA, Religa P, Clasper S, Garvin S, Galter D et al. PDGF$\mathrm{BB}$ induces intratumoral lymphangiogenesis and promotes lymphatic metastasis. Cancer Cell 2004; 6: 333-345.

62 Nagy JA, Vasile E, Feng D, Sundberg C, Brown LF, Manseau EJ et al. VEGF-A induces angiogenesis, arteriogenesis, lymphangiogenesis, and vascular malformations. Cold Spring Harb Symp Quant Biol 2002; 67 227-237.

63 Saito Y, Nakagami H, Morishita R, Takami Y, Kikuchi Y, Hayashi $\mathrm{H}$ et al. Transfection of human hepatocyte growth factor gene ameliorates secondary lymphedema via promotion of lymphangiogenesis. Circulation 2006; 114: 1177-1184

64 Bjorndahl M, Cao R, Nissen LJ, Clasper S, Johnson LA, Xue $Y$ et al. Insulin-like growth factors 1 and 2 induce lymphangiogenesis in vivo. Proc Natl Acad Sci USA 2005; 102: 15593-15598.
65 Maruyama K, li M, Cursiefen C, Jackson DG, Keino H, Tomita M et al. Inflammation-induced lymphangiogenesis in the cornea arises from CD11b-positive macrophages. J Clin Invest 2005; 115: 2363-2372.

66 Salven P, Mustjoki S, Alitalo R, Alitalo K, Rafii S. VEGFR-3 and CD133 identify a population of CD34+ lymphatic/vascular endothelial precursor cells. Blood 2003; 101: 168-172.

67 Kataru RP, Jung K, Jang C, Yang H, Schwendener RA, Baik JE et al. Critical role of $\mathrm{CD} 11 \mathrm{~b}+$ macrophages and VEGF in inflammatory lymphangiogenesis, antigen clearance, and inflammation resolution. Blood 2009; 113: 5650-5659.

68 Spyridonidis A, Zeiser R, Follo M, Metaxas Y, Finke J. Stem cell plasticity: The debate begins to clarify. Stem Cell Rev 2005; 1: 37-43.

69 Asahara T, Murohara T, Sullivan A, Silver M, van der Zee R, Li T et al. Isolation of putative progenitor endothelial cells for angiogenesis. Science 1997: 275: 964-967.

70 Takahashi T, Kalka C, Masuda H, Chen D, Silver M, Kearney M et al. Ischemia- and cytokine-induced mobilization of bone marrow-derived endothelial progenitor cells for neovascularization. Nat Med 1999; 5 434-438.

71 Kawamoto A, Gwon HC, Iwaguro H, Yamaguchi JI, Uchida S, Masuda H et al. Therapeutic potential of ex vivo expanded endothelial progenitor cells for myocardial ischemia. Circulation 2001; 103: 634-637.

72 Karpanen T, Alitalo K. Molecular biology and pathology of lymphangiogenesis. Ann Rev Pathol 2008; 3: 367-397.

73 He Y, Rajantie I, IImonen M, Makinen T, Karkkainen MJ, Haiko P et al. Preexisting lymphatic endothelium but not endothelial progenitor cells are essential for tumor lymphangiogenesis and lymphatic metastasis. Cancer Res 2004; 64: 3737-3740.

74 Kerjaschki D, Huttary N, Raab I, Regele H, Bojarski-Nagy K, Bartel G et al. Lymphatic endothelial progenitor cells contribute to de novo lymphangiogenesis in human renal transplants. Nat Med 2006; 12: 230-234.

75 Zumsteg A, Baeriswyl V, Imaizumi N, Schwendener R, Ruegg C Christofori G. Myeloid cells contribute to tumor lymphangiogenesis. Plos One 2009; 4: e7067.

76 Schoppmann SF, Birner P, Stockl J, Kalt R, Ullrich R, Caucig C et al. Tumor-associated macrophages express lymphatic endothelial growth factors and are related to peritumoral lymphangiogenesis. Am J Pathol 2002; 161: 947-956.

77 Blin-Wakkach C, Wakkach A, Quincey D, Carle GF. Interleukin-7 partially rescues $\mathrm{B}$-lymphopoiesis in osteopetrotic oc/oc mice through the engagement of $\mathrm{B} 220+\mathrm{CD} 11 \mathrm{~b}+$ progenitors. Exp Hematol 2006; 34 851-859.

78 Ferrara N, Davis-Smyth T. The biology of vascular endothelial growth factor. Endocr Rev 1997; 18: 4-25.

79 Leung DW, Cachianes G, Kuang WJ, Goeddel DV, Ferrara N. Vascular endothelial growth factor is a secreted angiogenic mitogen. Science 1989, 246: 1306-1309.

80 Weidenaar AC, ter Elst A, Koopmans-Klein G, Rosati S, den Dunnen WF, Meeuwsen-de Boer $T$ et al. High acute myeloid leukemia derived VEGFA levels are associated with a specific vascular morphology in the leukemic bone marrow. Cell Oncol 2011; 34: 289-296.

81 Hiramatsu A, Miwa H, Shikami M, Ikai T, Tajima E, Yamamoto H et al. Disease-specific expression of VEGF and its receptors in aml cells Possible autocrine pathway of VEGF/type1 receptor of VEGF in $t(15 ; 17)$ aml and VEGF/type2 receptor of VEGF in $\mathrm{t}(8 ; 21)$ aml. Leuk Lymphoma 2006; 47: 89-95.

82 Kim DH, Lee NY, Lee MH, Sohn SK, Do YR, Park JY. Vascular endothelial growth factor (VEGF) gene (VEGFA) polymorphism can predict the prognosis in acute myeloid leukaemia patients. Br J Haematol 2008; 140: $71-79$

83 Imai N, Shikami M, Miwa H, Suganuma K, Hiramatsu A, Watarai M et al. $T(8 ; 21)$ acute myeloid leukaemia cells are dependent on vascular endothelial growth factor (VEGF)/VEGF receptor type2 pathway and phosphorylation of AKT. Br J Hematol 2006; 135: 673-682.

84 Santos SC, Dias S. Internal and external autocrine VEGF/KDR loops regulate survival of subsets of acute leukemia through distinct signaling pathways. Blood 2004; 103: 3883-3889.

85 Wang Y, Nakayama M, Pitulescu ME, Schmidt TS, Bochenek ML, Sakakibara A et al. Ephrin-B2 controls VEGF-induced angiogenesis and lymphangiogenesis. Nature 2010; 465: 483-486.

86 Caceres-Cortes JR, Alvarado-Moreno JA, Waga K, Rangel-Corona R, Monroy-Garcia A, Rocha-Zavaleta L et al. Implication of tyrosine kinase receptor and steel factor in cell density-dependent growth in cervical cancers and leukemias. Cancer Res 2001; 61: 6281-6289. 
87 de Bont ES, Fidler V, Meeuwsen T, Scherpen F, Hahlen K, Kamps WA. Vascular endothelial growth factor secretion is an independent prognostic factor for relapse-free survival in pediatric acute myeloid leukemia patients. Clin Cancer Res 2002; 8: 2856-2861.

88 Aguayo A, Estey E, Kantarjian H, Mansouri T, Gidel C, Keating M et al. Cellular vascular endothelial growth factor is a predictor of outcome in patients with acute myeloid leukemia. Blood 1999; 94: 3717-3721.

89 Doepfner KT, Spertini O, Arcaro A. Autocrine insulin-like growth factor-I signaling promotes growth and survival of human acute myeloid leukemia cells via the phosphoinositide 3-kinase/Akt pathway. Leukemia 2007; 21: 1921-1930.

90 Chen X, Zheng J, Zou Y, Song C, Hu X, Zhang CC. IGF binding protein 2 is a cell-autonomous factor supporting survival and migration of acute leukemia cells. J Hematol Oncol 2013; 6: 72.

91 DeMambro VE, Maile L, Wai C, Kawai M, Cascella T, Rosen CJ et al. Insulin-like growth factor-binding protein-2 is required for osteoclast differentiation. J Bone Miner Res 2012; 27: 390-400.

92 Shah CA, Bei L, Wang H, Platanias LC, Eklund EA. The leukemia-associated MLL-ELL oncoprotein induces fibroblast growth factor 2 (FGF2)-dependent cytokine hypersensitivity in myeloid progenitor cells. J Biol Chem 2013; 288: 32490-32505.

93 Randolph GJ, Angeli V, Swartz MA. Dendritic-cell trafficking to lymph nodes through lymphatic vessels. Nat Rew Immunol 2005; 5: 617-628.

94 Swartz MA, Lund AW. Lymphatic and interstitial flow in the tumour microenvironment: Linking mechanobiology with immunity. Nat Rev Cancer 2012; 12: 210-219.

95 Kalkunte SS, Mselle TF, Norris WE, Wira CR, Sentman CL, Sharma S. Vascular endothelial growth factor $\mathrm{C}$ facilitates immune tolerance and endovascular activity of human uterine $\mathrm{nk}$ cells at the maternal-fetal interface. J Immunol 2009; 182: 4085-4092.

96 Skobe M, Hamberg LM, Hawighorst T, Schirner M, Wolf GL, Alitalo K et al. Concurrent induction of lymphangiogenesis, angiogenesis, and macrophage recruitment by vascular endothelial growth factor-c in melanoma. Am J Pathol 2001; 159: 893-903.

97 DeNardo DG, Andreu P, Coussens LM. Interactions between lymphocytes and myeloid cells regulate pro- versus anti-tumor immunity. Cancer Metastasis Rev 2010; 29: 309-316.

98 Krebs R, Tikkanen JM, Ropponen JO, Jeltsch M, Jokinen JJ, Yla-Herttuala $\mathrm{S}$ et al. Critical role of VEGF-C/VEGFR-3 signaling in innate and adaptive immune responses in experimental obliterative bronchiolitis. Am J Pathol 2012; 181: 1607-1620.

99 Sciume G, De Angelis G, Benigni G, Ponzetta A, Morrone S, Santoni A et al. CX3CR1 expression defines 2 KLRG1+ mouse NK-cell subsets with distinct functional properties and positioning in the bone marrow. Blood 2011: 117: 4467-4475.

100 Shao X, Liu C. Influence of IFN- alpha and IFN- gamma on lymphangiogenesis. J Interferon Cytokine Res 2006; 26: 568-574.

101 Fathallah-Shaykh HM, Zhao LJ, Kafrouni AI, Smith GM, Forman J. Gene transfer of IFN-gamma into established brain tumors represses growth by antiangiogenesis. J Immunol 2000; 164: 217-222.

102 Abraham SN, St John AL. Mast cell-orchestrated immunity to pathogens. Nat Rev Immunol 2010; 10: 440-452.

103 Oldford SA, Marshall JS. Mast cells as targets for immunotherapy of solid tumors. Mol Immunol 2014; 63: 113-124.

104 Bae MH, Kim HK, Park CJ, Seo EJ, Park SH, Cho YU et al. A case of systemic mastocytosis associated with acute myeloid leukemia terminating as aleukemic mast cell leukemia after allogeneic hematopoietic stem cell transplantation. Ann Lab Med 2013; 33: 125-129.

105 Nagai S, Ichikawa M, Takahashi T, Sato H, Yokota H, Oshima K et al. The origin of neoplastic mast cells in systemic mastocytosis with AML1/ETO-positive acute myeloid leukemia. Exp Hematol 2007; 35: 1747-1752.

106 Bohmer R, Neuhaus B, Buhren S, Zhang D, Stehling M, Bock B et al. Regulation of developmental lymphangiogenesis by Syk(+) leukocytes. Dev Cell 2010; 18: 437-449.

107 Angeli V, Ginhoux F, Llodra J, Quemeneur L, Frenette PS, Skobe M et al. $B$ cell-driven lymphangiogenesis in inflamed lymph nodes enhances dendritic cell mobilization. Immunity 2006; 24: 203-215.

108 Murakami M, Zheng Y, Hirashima M, Suda T, Morita Y, Ooehara J et al. VEGFR1 tyrosine kinase signaling promotes lymphangiogenesis as well as angiogenesis indirectly via macrophage recruitment. Arterioscler Thromb Vasc Bio 2008; 28: 658-664.
109 Cursiefen C, Chen L, Borges LP, Jackson D, Cao J, Radziejewski C et al. VEGF-A stimulates lymphangiogenesis and hemangiogenesis in inflammatory neovascularization via macrophage recruitment. J Clin Invest 2004: 113: 1040-1050.

110 Skobe M. Lymphatic vessels and cancer. Lymphatic Res Biol 2012; 10: 96.

111 Stacker SA, Williams SP, Karnezis T, Shayan R, Fox SB, Achen MG. Lymphangiogenesis and lymphatic vessel remodelling in cancer. Nat Rev Cancer 2014; 14: 159-172.

112 Ishikawa F, Yoshida S, Saito Y, Hijikata A, Kitamura H, Tanaka S et al. Chemotherapy-resistant human aml stem cells home to and engraft within the bone-marrow endosteal region. Nat Biotechnol 2007; 25: $1315-1321$.

113 Sacchetti B, Funari A, Michienzi S, Di Cesare S, Piersanti S, Saggio I et al. Self-renewing osteoprogenitors in bone marrow sinusoids can organize a hematopoietic microenvironment. Cell 2007; 131: 324-336.

114 Arai F, Hirao A, Ohmura M, Sato H, Matsuoka S, Takubo K et al. Tie2/angiopoietin-1 signaling regulates hematopoietic stem cell quiescence in the bone marrow niche. Cell 2004; 118: 149-161.

$115 \mathrm{Li}$ Y, Chen S, Yuan J, Yang Y, Li J, Ma J et al. Mesenchymal stem/progenitor cells promote the reconstitution of exogenous hematopoietic stem cells in FANCG-/- mice in vivo. Blood 2009; 113: 2342-2351.

116 Kwon KR, Ahn JY, Kim MS, Jung JY, Lee JH, Oh IH. Disruption of BIS leads to the deterioration of the vascular niche for hematopoietic stem cells. Stem Cells 2010; 28: 268-278.

117 Schietroma C, Cianfarani F, Lacal PM, Odorisio T, Orecchia A, Kanitakis J et al. Vascular endothelial growth factor-C expression correlates with lymph node localization of human melanoma metastases. Cancer 2003; 98: 789-797.

118 Mohammed RA, Green A, El-Shikh S, Paish EC, Ellis IO, Martin SG. Prognostic significance of vascular endothelial cell growth factors $-A,-C$ and $-D$ in breast cancer and their relationship with angio- and lymphangiogenesis. Br J Cancer 2007; 96: 1092-1100.

119 Renyi-Vamos F, Tovari J, Fillinger J, Timar J, Paku S, Kenessey I et al. Lymphangiogenesis correlates with lymph node metastasis, prognosis, and angiogenic phenotype in human non-small cell lung cancer. Clin Cancer Res 2005; 11: 7344-7353.

120 Bullinger L, Dohner K, Bair E, Frohling S, Schlenk RF, Tibshirani R et al. Use of gene-expression profiling to identify prognostic subclasses in adult acute myeloid leukemia. N Engl J Med 2004; 350: 1605-1616.

121 Dias S, Shmelkov SV, Lam G, Rafii S. VEGF(165) promotes survival of leukemic cells by Hsp90-mediated induction of $\mathrm{Bcl}-2$ expression and apoptosis inhibition. Blood 2002; 99: 2532-2540.

122 Liersch R, Schliemann C, Bieker R, Hintelmann H, Buechner T, Berdel WE et al. Expression of VEGF-C and its receptor VEGFR-3 in the bone marrow of patients with acute myeloid leukaemia. Leuk Res 2008; 32: 954-961.

123 Liersch R, Shin JW, Bayer M, Schwoppe C, Schliemann C, Berdel WE et al. Analysis of a novel highly metastatic melanoma cell line identifies osteopontin as a new lymphangiogenic factor. Int J Oncol 2012; 41: $1455-1463$.

124 Liersch R, Gerss J, Schliemann C, Bayer M, Schwoppe C, Biermann C et al. Osteopontin is a prognostic factor for survival of acute myeloid leukemia patients. Blood 2012; 119: 5215-5220.

125 Ossenkoppele GJ, Stussi G, Maertens J, van Montfort K, Biemond BJ, Breems $D$ et al. Addition of bevacizumab to chemotherapy in acute myeloid leukemia at older age: A randomized phase 2 trial of the dutch-belgian cooperative trial group for hemato-oncology (hovon) and the swiss group for clinical cancer research (sakk). Blood 2012; 120: 4706-4711.

126 Albers C, Leischner H, Verbeek M, Yu C, Illert AL, Peschel C et al. The secondary FLT3-ITD F691I mutation induces resistance to AC220 in FLT3-ITD+ AML but retains in vitro sensitivity to PKC412 and sunitinib. Leukemia 2013; 27: 1416-1418.

127 Fiedler W, Serve H, Dohner H, Schwittay M, Ottmann OG, O'Farrell AM et al. A phase 1 study of SU11248 in the treatment of patients with refractory or resistant acute myeloid leukemia (AML) or not amenable to conventional therapy for the disease. Blood 2005; 105: 986-993.

128 Karp JE, Gojo I, Pili R, Gocke CD, Greer J, Guo C et al. Targeting vascular endothelial growth factor for relapsed and refractory adult acute myelogenous leukemias: Therapy with sequential 1-beta-d-arabinofuranosylcytosine, mitoxantrone, and bevacizumab. Clin Cancer Res 2004; 10: 3577-3585. 
129 Roboz GJ, Giles FJ, List AF, Cortes JE, Carlin R, Kowalski M et al. Phase 1 study of PTK787/ZK 222584, a small molecule tyrosine kinase receptor inhibitor, for the treatment of acute myeloid leukemia and myelodysplastic syndrome. Leukemia 2006; 20: 952-957.

130 Fiedler W, Mesters R, Tinnefeld H, Loges S, Staib P, Duhrsen U et al. A phase 2 clinical study of SU5416 in patients with refractory acute myeloid leukemia. Blood 2003; 102: 2763-2767.

131 Persaud K, Tille JC, Liu M, Zhu Z, Jimenez X, Pereira DS et al. Involvement of the VEGF receptor 3 in tubular morphogenesis demonstrated with a human anti-human VEGFR-3 monoclonal antibody that antagonizes receptor activation by VEGF-C. J Cell Sci 2004; 117: 2745-2756.

132 Hudkins RL, Becknell NC, Zulli AL, Underiner TL, Angeles TS, Aimone LD et al. Synthesis and biological profile of the pan-vascular endothelial growth factor receptor/tyrosine kinase with immunoglobulin and epidermal growth factor-like homology domains 2 (VEGF-R/TIE-2) inhibitor 11-(2-methylpropyl)-12,13-dihydro-2-methyl-8(pyrimidin-2-ylamino)-4H-indazolo[5, 4-a]pyrrolo[3,4-c]carbazol-4-one (cep-11981): A novel oncology therapeutic agent. J Med Chem 2012; 55: 903-913.

133 Hajrasouliha AR, Funaki T, Sadrai Z, Hattori T, Chauhan SK, Dana R. Vascular endothelial growth factor-c promotes alloimmunity by amplifying antigen-presenting cell maturation and lymphangiogenesis. Invest Ophthalmol Vis Sci 2012; 53: 1244-1250.

134 Hamberg $P$, Boers-Sonderen MJ, van der Graaf WT, de Bruijn P, Suttle AB, Eskens FA et al. Pazopanib exposure decreases as a result of an ifosfamide-dependent drug-drug interaction: Results of a phase i study. Br J Cancer 2014; 110: 888-893.

135 Belani CP, Yamamoto N, Bondarenko IM, Poltoratskiy A, Novello S, Tang $\mathrm{J}$ et al. Randomized phase ii study of pemetrexed/cisplatin with or without axitinib for non-squamous non-small-cell lung cancer. BMC cancer 2014; 14: 290.
136 Davis SL, Eckhardt SG, Messersmith WA, Jimeno A. The development of regorafenib and its current and potential future role in cancer therapy. Drugs Today (Barc) 2013; 49: 105-115.

137 D'Amato RJ, Lentzsch S, Rogers MS. Pomalidomide is strongly antiangiogenic and teratogenic in relevant animal models. Proc Natl Acad Sci USA 2013; 110: E4818.

138 Davies FE, Raje N, Hideshima T, Lentzsch S, Young G, Tai YT et al. Thalidomide and immunomodulatory derivatives augment natural killer cell cytotoxicity in multiple myeloma. Blood 2001; 98: 210-216.

139 Tazzari PL, Tabellini G, Bortul R, Papa V, Evangelisti C, Grafone T et al. The insulin-like growth factor-I receptor kinase inhibitor NVP-AEW541 induces apoptosis in acute myeloid leukemia cells exhibiting autocrine insulin-like growth factor-I secretion. Leukemia 2007; 21: 886-896.

140 Kentsis A, Reed C, Rice KL, Sanda T, Rodig SJ, Tholouli E et al. Autocrine activation of the met receptor tyrosine kinase in acute myeloid leukemia. Nat Med 2012; 18: 1118-1122.

141 Neal J, Wakelee H. AMG-386 a selective angiopoietin-1/-2-neutralizing peptibody for the potential treatment of cancer. Curr Opin Mol Ther 2010; 12: 487-495.

(c) (i) () $\odot$ This work is licensed under a Creative Commons Attribution-NonCommercial-NoDerivs 3.0 Unported License. The images or other third party material in this article are included in the article's Creative Commons license, unless indicated otherwise in the credit line; if the material is not included under the Creative Commons license, users will need to obtain permission from the license holder to reproduce the material. To view a copy of this license, visit http://creativecommons.org/licenses/by-nc-nd/3.0/ 